\title{
Analysis on the Influence Degree of Deformation Control Factors of Deep-Buried Roadway's Fractured Surrounding Rock Using Orthogonal Design
}

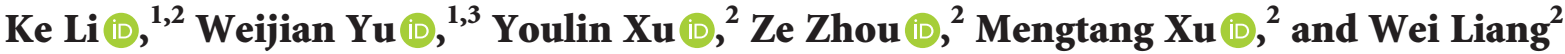 \\ ${ }^{1}$ School of Resource \& Environment and Safety Engineering, Hunan University of Science and Technology, Xiangtan, \\ Hunan 411201, China \\ ${ }^{2}$ College of Mining, Guizhou Institute of Technology, Guiyang, Guizhou 550003, China \\ ${ }^{3}$ Hunan Provincial Key Laboratory of Safe Mining Techniques of Coal Mines, Hunan University of Science and Technology, \\ Xiangtan, Hunan 411201, China \\ Correspondence should be addressed to Weijian Yu; ywjlah@163.com
}

Received 1 April 2021; Accepted 23 May 2021; Published 7 June 2021

Academic Editor: Zhijie Zhu

Copyright (C) $2021 \mathrm{Ke} \mathrm{Li} \mathrm{et} \mathrm{al.} \mathrm{This} \mathrm{is} \mathrm{an} \mathrm{open} \mathrm{access} \mathrm{article} \mathrm{distributed} \mathrm{under} \mathrm{the} \mathrm{Creative} \mathrm{Commons} \mathrm{Attribution} \mathrm{License,} \mathrm{which}$ permits unrestricted use, distribution, and reproduction in any medium, provided the original work is properly cited.

\begin{abstract}
It is a complex issue to select the support structure parameters for a deep-buried roadway with fractured surrounding rock; especially when the support structure parameters need to be adjusted, the influence degree of support structure parameters on roadway deformation needs to be determined. The deformation of deep-buried roadway's fractured surrounding rock development was investigated using multi-index orthoplan in this paper. According to the coal mine field investigation, support structure's failure often occurs, and some need to be repaired many times. Through the roadway surrounding rock drilling, it was found that the stress of the surrounding rock was relieved, resulting in the cavity and separation of the stratum layer. The two sidewalls' development and roof fractures are mainly tangential, and the original rock state appears only beyond $6.3 \sim 8.2 \mathrm{~m}$. The length of bolts, the row distance between bolts, the length of cables, and the row distance of U-shaped steel were selected as control factors in the multi-index orthogonal design, and roadway's deformation values were taken as the test indexes. According to the orthoplan, nine numerical simulation schemes were designed, and $\mathrm{FLAC}^{3 \mathrm{D}}$ was used for establishment. The range analysis method was used to analyze the test results. The results show that the control factors' influence order on the total deformation of the roadway is as follows: row spacing between U-shaped steel > bolt length > cable length > row spacing between bolts, the influence order on the deformation of the roadway floor is as follows: row spacing between U-shaped steel $>$ row spacing between bolts $>$ bolt length $>$ cable length, same as the left sidewall and right sidewall, and the influence order on the roadway roof's deformation is as follows: row spacing between $\mathrm{U}$-shaped steel $>$ bolt length $=$ cable length $>$ row spacing between bolts, which provide a reference for the support design of deep-buried roadways with fractured surrounding rock, especially the adjustment of the supporting structure.
\end{abstract}

\section{Introduction}

With the shallow resource mined out, the coal mining gradually shifts to the deep. The factors such as significant buried depth, high-stress environment, complex structure, broken surrounding rock, and aquifer influence are superimposed, bringing about more challenges to the maintenance of coal mine roadway [1]. The deep-buried soft rock roadway's maintenance difficulty gradually becomes the bottleneck of building high-efficiency mines. Choosing the appropriate supporting method is challenging to solve urgently in the coal mine site.

In the Yunnan-Guizhou plateau of Southwest China, coal mines are greatly affected by geological structure. Under the vigorous promotion of many scholars and engineers, bolts (cables), section steel, shotcrete (grouting), and other support technologies are widely used in coal mine field $[2,3]$. The exploration of support structure mechanism and its 
bearing mechanism with surrounding rock has always been the focus of academic research and engineering practice. Many significant achievements have emerged and solved many engineering and technical problems. Batugin et al. [4] developed a combined support technology for adjacent roadways and analyzed for a rock bolt and anchor cable mechanism based on the external staggered split-level panel layout's spatial structure. Yu et al. [5] and $\mathrm{Wu}$ et al. [6] proposed a combined control scheme based on the bearing system of the "long-short" bolt (cable) and the controlled grouting reinforcement of the "internal-external" structure. Gong et al. [7] and Li et al. [8] considered that the radial stress had a greater effect on the spalling failure under the three-dimensional stress condition than the axial stress. Zhang et al. [9] established a mechanical model concerning roof separation within and outside the anchorage zone above the backfill area of gob-side entry retaining and derived a formula to calculate the roof separation, whose influence factors and law were also obtained. Zuo et al. $[10,11]$ analyzed the stress distribution and failure mechanism of surrounding rock for deep underground project based on brittle constitutive model and slippage destruction theory and considered that excavation unloading would cause the growth of the shear stress, which leads to the local irreversible (plastic) slip or break, and the surrounding rock will be divided into blocks with a certain scale; the frictions between the blocks decide the value of the rest strength. Zhang et al. [12] built a mechanical model of roadway stress based on the nonconstant pressure force state and the cracks revolution mechanisms of floor roadway surrounding rock. Li et al. [13] presented a discontinuous elastoplastic model for the plane strain to depict rock shear strain localization phenomenon and considered that the discontinuous model could profoundly describe the postpeak shear localization phenomenon of the deep rock mass. Huang et al. [14] considered that the large deformation of roadways includes the large deformation of the whole movement caused by the large structure instability of the overlying strata and the large deformation of the movement of the fractured rock mass in the loosening circle. Yan et al. [15] proposed a model for end-anchored rock bolts loaded in tension by implementing a novel tensile failure criterion as part of a $3 \mathrm{D}$ continuum numerical modeling package. Zhu et al. [16] developed a parametric asymmetric Voronoi block generation program by Python and established the roadway's numerical model by combining the results of exploration test, micro properties calibration, tension and shear test of rock bolt, and bearing characteristics of timber.

Due to the complexity of fractured rock mass, control technology of roadway with fractured surrounding rock has not yet formed a mature system. At present, the combination of passive support and active support is mainly used, such as steel, bolts, cables, and grouting scheme [12, 17]. However, due to the significant difference in the rock mass, both the stability of rock mass and the control of surrounding rock should be adopted to local conditions $[18,19]$. Coal mine's sedimentary environment and structural environment are complex in the Yunnan-Guizhou Plateau of Southwest China. Most of the rock engineering encountered is low strength fractured rock mass, which has low integrity and poor overall strength and is easy to cause large deformation or instability.

The orthogonal design is used to carry out multiple combinations of supporting structure parameters to determine the influence degree of supporting structure parameters on the supporting effect, which provides a reference for the support design of deep-buried roadway with fractured surrounding rock, especially the adjustment of supporting structure.

\section{Engineering Background}

2.1. Basic Information. Wanshun coal mine in Tongzi County, Guizhou Province, is located in the northeast of Songkan syncline. The mining elevation is $+1200 \sim \pm 0 \mathrm{~m}$, and the maximum mining depth is $1500 \mathrm{~m}$. There are three minable coal seams, which are numbered C5, C3, and C1, respectively. The coal seams' inclination angle is $65^{\circ} \sim 90^{\circ}$, the coal seams above the elevation of $+700 \mathrm{~m}$ in the minefield are inverted, and the coal seams are upright in the range of $+500 \mathrm{~m} \sim+700 \mathrm{~m}$. Minable coal seams are all present in the Permian Longtan Formation $\left(\mathrm{P}_{3} l\right)$, and the upper strata of $\mathrm{P}_{3} l$ are in the Permian Changxing Formation $\left(\mathrm{P}_{3} c\right)$, belonging to medium to thickly layered limestone with suture structure and thinner layered marl, with well-developed joints and fissures. The underlying strata of $\mathrm{P}_{3} l$ are in the Permian Maokou Formation $\left(\mathrm{P}_{2} m\right)$, which is a strong aquifer.

2.2. Roadway Layout. Wanshun coal mine is the second mining area. There are four raises in the mining area located in $\mathrm{P}_{3} c$ and marl of Yulongshan member of Yelang Formation $\left(T_{1} y^{2}\right)$. To eliminate the risk of gas outburst in the coal seam and shorten the service life of headentries and tailentries in coal mining face, before crossheadings enter the coal seam, main transportation and ventilated roadways are arranged in $\mathrm{P}_{3} c$ between raises and coal seam. After the danger of gas outburst is eliminated, the crossheadings will be constructed from main roadways to coal seam every $200 \mathrm{~m}$, and the headentries and tailentries are arranged after exposing coal seam. According to the field investigation, the second mining area's surrounding rock, which is now arranged in $T_{1} y^{2}$, is relatively stable and deformed. The surrounding rock joints and fissures of the raise and concentrated roadway in $\mathrm{P}_{3} \mathrm{C}$ are developed (Figure 1). The 550 main roadway arranged in $\mathrm{P}_{3} \mathrm{C}$ and $40 \mathrm{~m}$ away from C5 was considered an engineering background. The roadway layout is shown in Figure 2.

2.3. Roadway Support and Deformation. The 550 main roadway has a semicircular arch section, with a clear width of $3.6 \mathrm{~m}$, a wall height of $1.4 \mathrm{~m}$, an arch height of $1.8 \mathrm{~m}$, a section of $10.0 \mathrm{~m}^{2}$, and a buried depth of $700 \mathrm{~m}$. The original support method of the roadway is bolting with wire mesh and shotcrete. The bolts adopt resin anchored steel anchor rod, the diameter of the bolts is $18 \mathrm{~mm}$, the length is $2.2 \mathrm{~m}$, and the row distance between the bolts is $900 \times 900 \mathrm{~mm}$. 


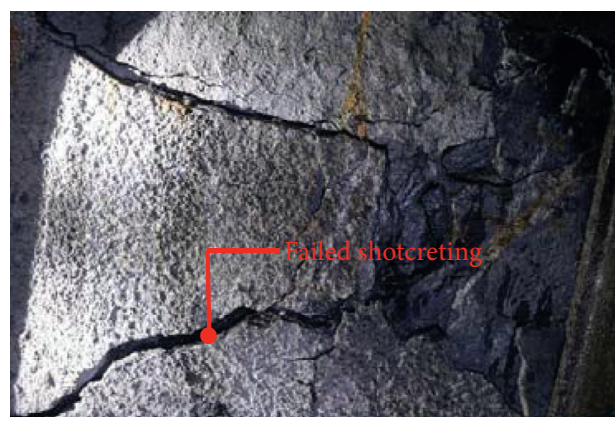

(a)

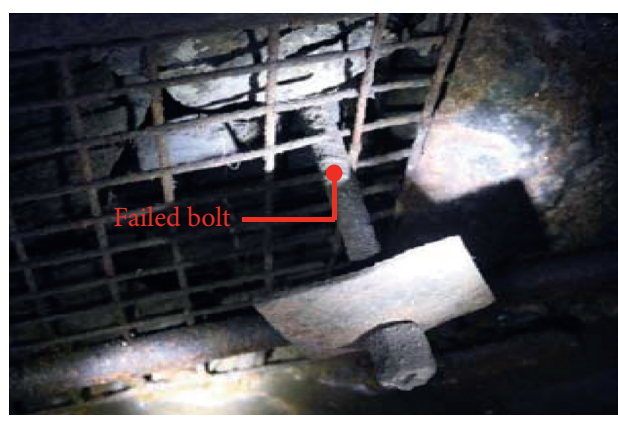

(c)

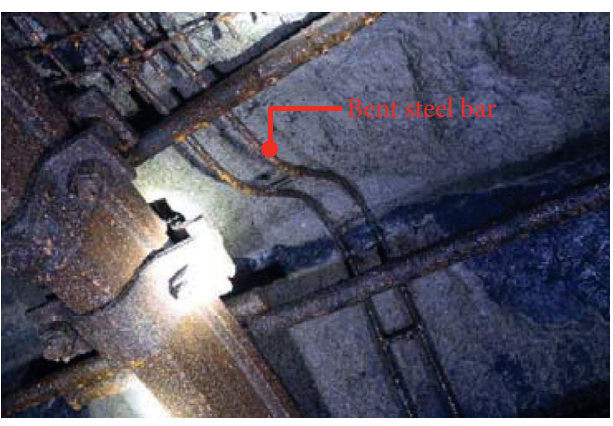

(b)

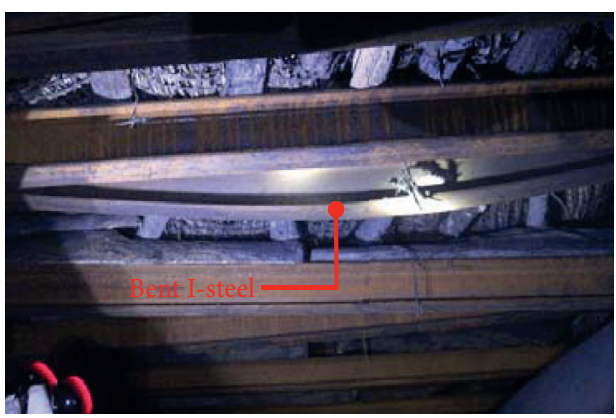

(d)

Figure 1: Current status of the support structure.

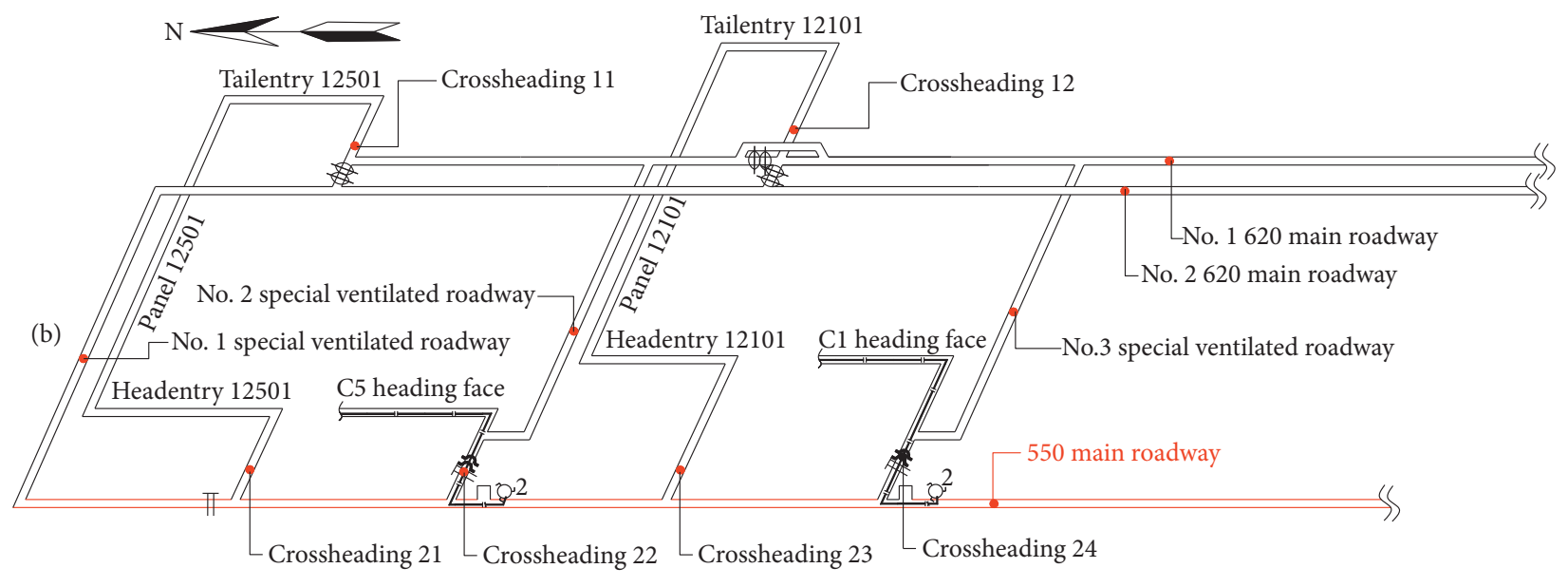

Figure 2: Schematic diagram of the roadway layout.

According to the field investigation, the roof subsidence is close to $1.0 \mathrm{~m}$, and the arch wall on the far coal side cracks and falls seriously in the spray layer (as shown in Figure 1(a)). The roadway has been repaired many times. The steel ladder and bolts were repaired for the second time. The roadway continued to deform, most of the bolts failed, and the steel ladder was squeezed and deformed (as shown in Figure 1(b)), whereafter part of the roadway was changed to I-steel + bolt + cables, but the bolts and cables failed in an extensive range (as shown in Figure 1(c)). The I-steel was bent, and the roadway deformation was still not effectively controlled. At present, some sections have been forced to use retractable U-shaped steel flexible supports for support, and the roadway is still undergoing continuous and rapid deformation (as shown in Figure 1(d)).

\section{Analysis of Fractures and Mining Impact}

3.1. Surrounding Rock Fragmentation. To observe the two sidewalls and roof's damage of 550 main roadway after excavation, measurement point was arranged at a distance of $100 \mathrm{~m}$ from the raise of the second mining area, and three boreholes were constructed on the two sidewalls and the roof. Observed by CXK12 stratascope, the borehole depth is $15 \mathrm{~m}$. The peeking result shows that primary fissures dominate the surrounding rock with small extension length, 
no voids, and a small amount of fragmentation within $2 \mathrm{~m}$ of the shallow part. The results of stratascope are shown in Figure 3.

Peeping data from the measurement point show that the roof of the roadway deforms significantly; within $1.8 \mathrm{~m}$, it is completely broken and broken, and there are large cavities and separations at $3.6 \mathrm{~m}, 5.0 \mathrm{~m}, 6.2 \mathrm{~m}, 8.0 \mathrm{~m}$, etc., and it presents the original rock state only after $8.2 \mathrm{~m}$. The right sidewall was broken within $1.3 \mathrm{~m}$, and disturbed fissures developed within the range of $1.6 \sim 5.0 \mathrm{~m}$, but no cavity or separation layer was produced. The left sidewall is broken and damaged within $1.8 \mathrm{~m}$, and, after $1.8 \mathrm{~m}$, fissures develop at $2.4 \mathrm{~m}, 2.7 \mathrm{~m}, 3.0 \mathrm{~m}$, etc., and there are radial fractures. After $6.3 \mathrm{~m}$, the original rock state appears. The fractures in the two sidewalls and the roof are dominated by the tangential direction, expanding to form voids and separation layers.

\subsection{Damage Scope of the Mined-Out Area}

(1) If the damage depth of the goaf exceeds the location of the roadway, that is, the roadway is arranged in the crack zone or collapse zone, the surrounding rock of the roadway will lose stability as a whole, and the roadway will be in a large deformed and broken environment for a long time. The existing common coal mine support technology cannot control its long-term deformation and destruction. Therefore, if the roadway is in the goaf's damage range, the roadway location should be changed, and the roadway should be rearranged, and the roadway deformation problem should not be solved from the perspective of support.

The coal seam within the range of $+500 \mathrm{~m} \sim+550 \mathrm{~m}$ within the minefield is close to upright, and the formation above $+550 \mathrm{~m}$ is inverted. Therefore, the research object belongs to the coal seam floor above $+550 \mathrm{~m}$ and the roof of the coal seam below $+500 \mathrm{~m}$. The methods of actual measurement of the destruction depth of the roof and floor of the goaf mainly include the liquid leakage method, microseismic monitoring method, strain measurement method, and double-ended water plugging method of drilling holes. At present, the mined-out area of a mining area has been closed, and its destruction depth cannot be measured. This paper adopts the theoretical calculation method to calculate the destruction depth after considering the safety margin.

(2) Depth of damage to the floor: according to the regression analysis of the measured data, Sun et al. [20] obtained the floor failure depth equation:

$h_{1}=0.1105 L+0.006 H+0.4514 F-0.0085 \alpha$,

where $h_{1}$ is the depth of floor failure, $m$; $L$ is the panel's slope length, which is $100 \mathrm{~m} ; H$ is the coal mining depth, which is $750 \mathrm{~m} ; F$ is the
Protodyakonov coefficient; and $\alpha$ is the coal seam inclination, which is $90^{\circ}$. The calculation result of equation (1) differs from the actual measured value by $\pm 15 \%$. In this paper, the surplus coefficient is $20 \%$. From this calculation, the damage depth of the mine floor is $16.3 \mathrm{~m}$.

(3) Depth of roof damage: the caving zone and fracture zone in the goaf of steep coal seams generally present a uniform ear shape or asymmetrical arch up and down, and the height of the fracture zone is calculated using the following statistical equation [21]:

$$
h_{2}=\frac{100 M h}{7.5 h+293} \pm 7.3 \text {, }
$$

where $h_{2}$ is the fracture zone's height, $\mathrm{m} ; M$ is the mining thickness, which is $2 \mathrm{~m}$; and $h$ is the section's vertical height. The vertical height of the research mine section is not fixed, and the maximum is $100 \mathrm{~m}$. Calculated by equation (2), the fracture zone's height in the goaf is in the range of $11.9 \mathrm{~m}$ to $26.5 \mathrm{~m}$.

The calculation results of equations (1) and (2) are smaller than the distance between the 550 main roadway and the C5 coal seam. Therefore, the 550 main roadway is not within the crack zone or collapse zone of the goaf.

\section{Orthogonal Experimental Design}

Many factors influence the effect of roadway support in underground coal mines, such as the layer position of the roadway layout, the environment of considerable buried depth, the structural environment, the water content of the formation, and the support engineering. For the above influencing factors, only the support engineering can be very convenient. Therefore, based on the original support plan, this article used the orthogonal test method to determine the degree of influence of the support structure parameters on the roadway support effect.

The combined support plan of bolt + anchor cable + shotcrete + wire mesh + U-shaped steel was adopted. Technical standards require the shotcrete in this scheme, and there is not much room for optional wire mesh parameters, so it is determined that the bolt length, row spacing between bolts, cable length, and row spacing between U-shaped steel are the control factors. The deformation of the roadway is used as the test index. The level values of the main control factors of the scheme are shown in Table 1.

If all combinations of four factors, three levels of each factor, are to be examined, the number of tests to be performed is $3^{4}=81$. It is a hefty workload. The selective test is carried out by orthogonal design, and only nine tests are required. The orthogonal test is given in Table 2 .

The numerical models of roadway support in the above nine tests are shown in Figure 4, and the parameters of each support scheme marked in the figure correspond to each test scheme in Table 2. 


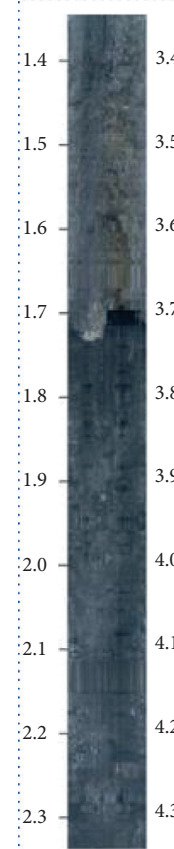

(a)

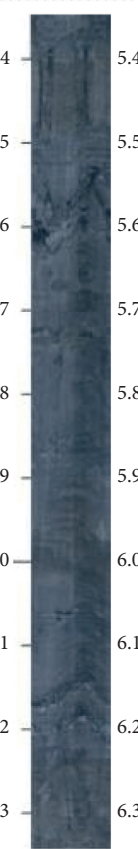

(b)

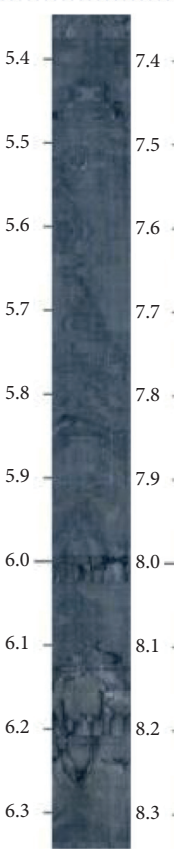

(c)

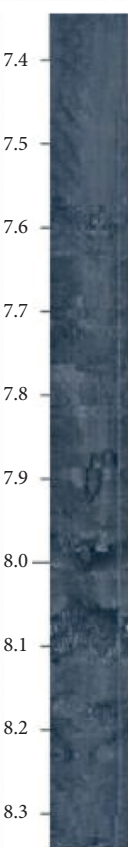

(d)

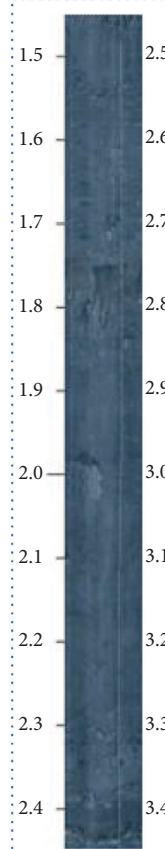

(e)

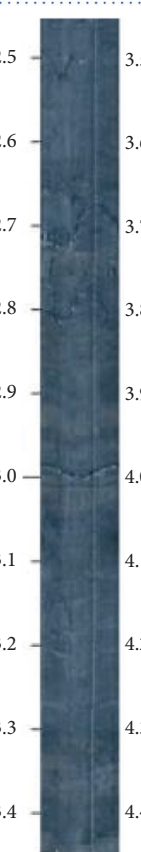

(f)

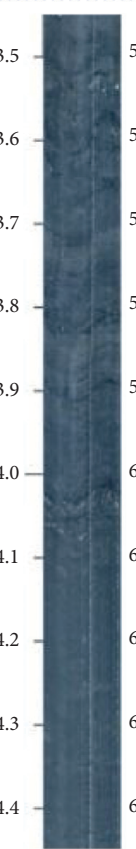

(g)

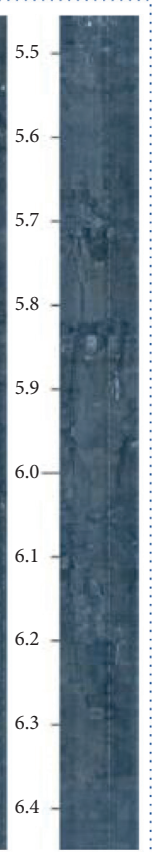

(h)

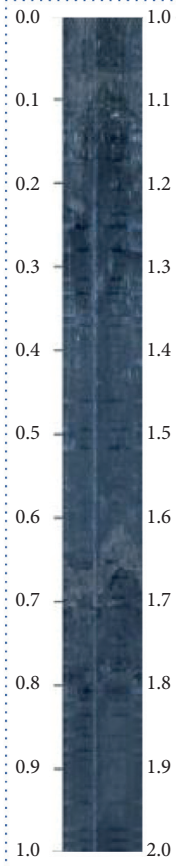

(i)

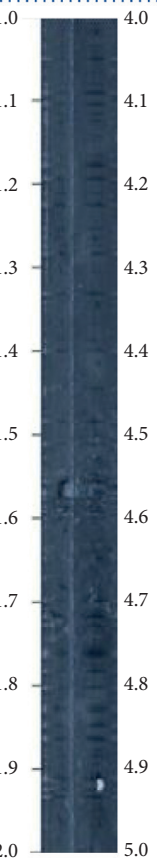

(j)

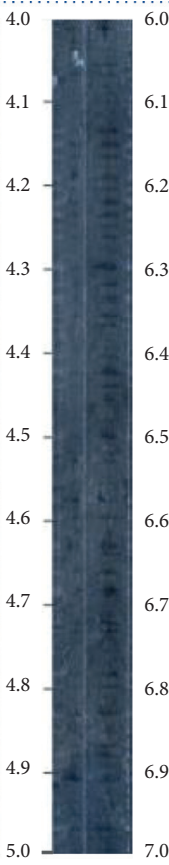

(k)

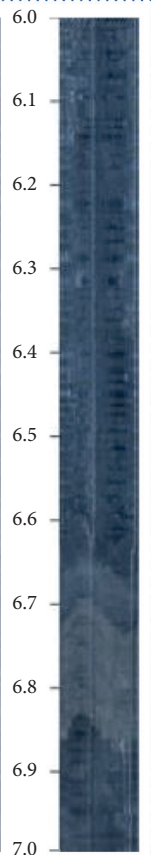

(1)

Figure 3: Chart of borehole netting.

Right sidewall bore

TABLE 1: The level value of the main control factors.

\begin{tabular}{lccc}
\hline Main control factors & Level 1 & Level 2 & Level 3 \\
\hline Bolt length $(\mathrm{m})$ & 2.0 & 2.5 & 3.0 \\
Row spacing between bolts $(\mathrm{m} \times \mathrm{m})$ & $0.6 \times 0.6$ & $0.8 \times 0.8$ & $1.0 \times 1.0$ \\
Cable length $(\mathrm{m})$ & 5 & 7 & 9 \\
Row spacing in U-shaped steel $(\mathrm{m})$ & 0.4 & 0.7 & 1.0 \\
\hline
\end{tabular}

TABLE 2: The orthogonal table of control factors $L_{9}\left(3^{4}\right)$.

\begin{tabular}{ccccc}
\hline & & \multicolumn{3}{c}{ Main control factors } \\
No. & Bolt length $\left(L_{\mathrm{b}}, \mathrm{m}\right)$ & Row spacing between bolts $\left(D_{\mathrm{b}}, \mathrm{m} \times \mathrm{m}\right)$ & Cable length $\left(L_{\mathrm{c}}, \mathrm{m}\right)$ & Row spacing in $\mathrm{U}$-shaped steel $\left(D_{\mathrm{u}}, \mathrm{m}\right)$ \\
\hline $\mathrm{T}_{1}$ & 2.0 & $0.6 \times 0.6$ & 5 & 0.4 \\
$\mathrm{~T}_{2}$ & 2.0 & $0.8 \times 0.8$ & 7 & 0.7 \\
$\mathrm{~T}_{3}$ & 2.0 & $1.0 \times 1.0$ & 9 & 1.0 \\
$\mathrm{~T}_{4}$ & 2.5 & $0.6 \times 0.6$ & 7 & 1.0 \\
$\mathrm{~T}_{5}$ & 2.5 & $0.8 \times 0.8$ & 9 & 0.4 \\
$\mathrm{~T}_{6}$ & 2.5 & $1.0 \times 1.0$ & 5 & 0.7 \\
$\mathrm{~T}_{7}$ & 3.0 & $0.6 \times 0.6$ & 9 & 0.7 \\
$\mathrm{~T}_{8}$ & 3.0 & $0.8 \times 0.8$ & 5 & 1.0 \\
$\mathrm{~T}_{9}$ & 3.0 & $1.0 \times 1.0$ & 7 & 0.4 \\
\hline
\end{tabular}

\section{Numerical Simulation}

5.1. Calculation Model and Scheme. The damage of 550 main roadway located in $\mathrm{P}_{3} \mathrm{C}$ is simulated based on FLAC ${ }^{3 \mathrm{D}}$, and the model size is $x \times y \times z=150 \mathrm{~m} \times 20 \mathrm{~m} \times 150 \mathrm{~m}$. The extrusion module of FLAC ${ }^{3 \mathrm{D}}$ is used to build the model. The number of zones in the model is 838,400 , and the number of nodes is 868,936 . The Mohr-Coulomb constitutive model was used. The model includes $\mathrm{P}_{3} l, \mathrm{P}_{3} c$, and $\mathrm{P}_{2} m$. Considering the formation inversion, the lower stratum and coal seam's dip angle is $80^{\circ}$, and the upper part is $100^{\circ}$ in the model. The upper part of the model is the bearing boundary, the buried depth of the top of the model is about $650 \mathrm{~m}$, the surface force of $15.9 \mathrm{MPa}$ is loaded on the top of the model, and the other five surfaces of the model are fixed by Fix command. The origin of the model is located in the 


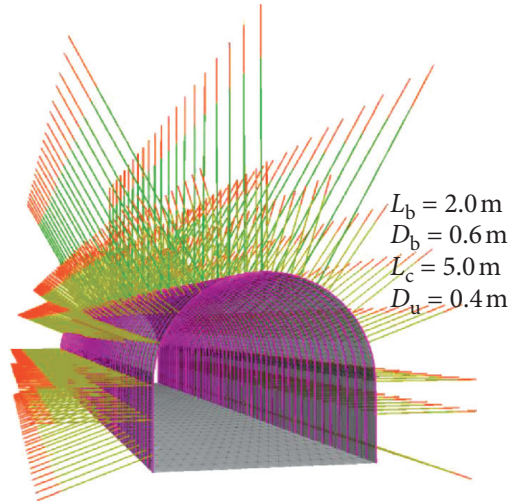

(a)

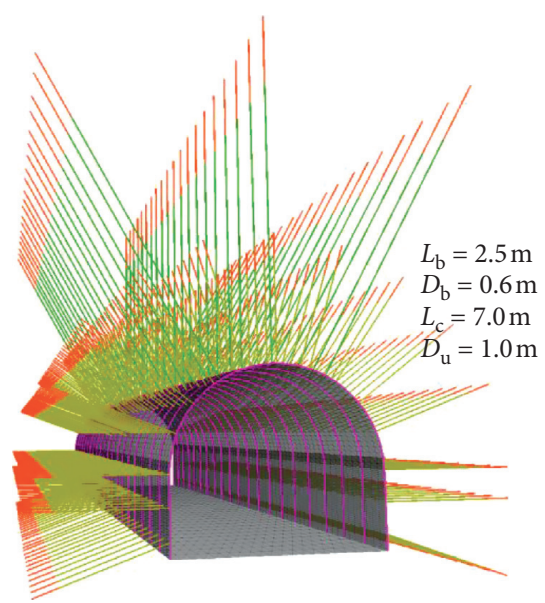

(d)

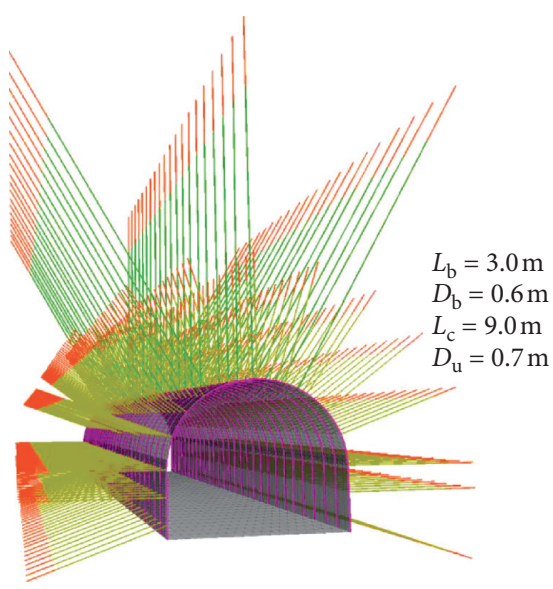

(g)

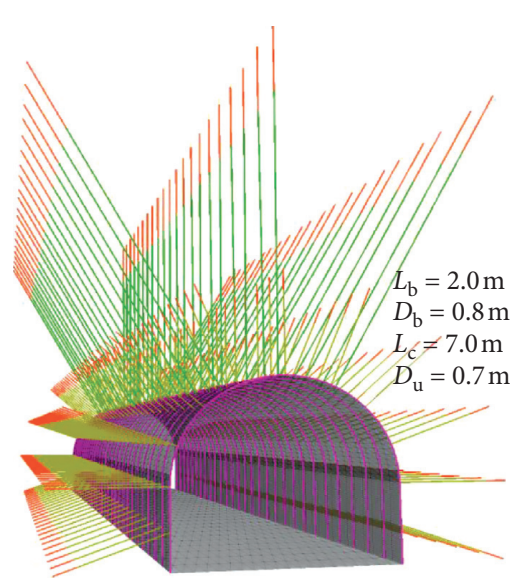

(b)

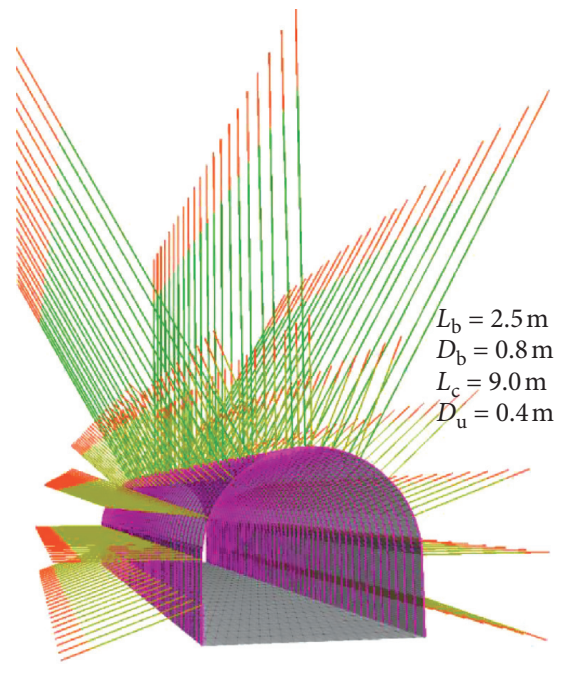

(e)

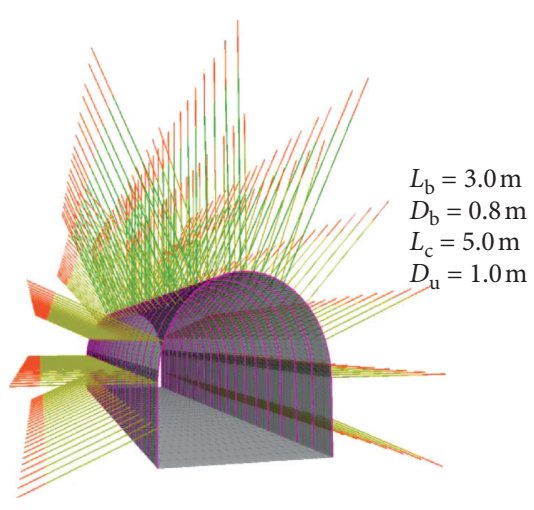

(h)

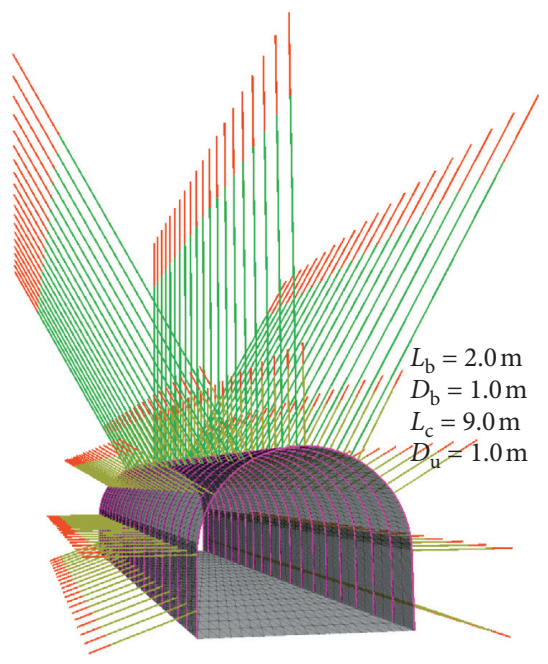

(c)

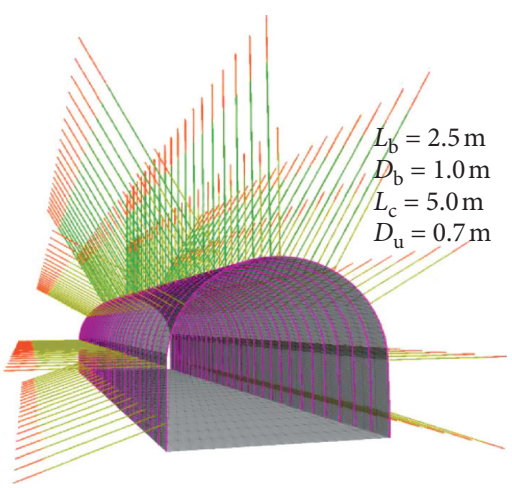

(f)

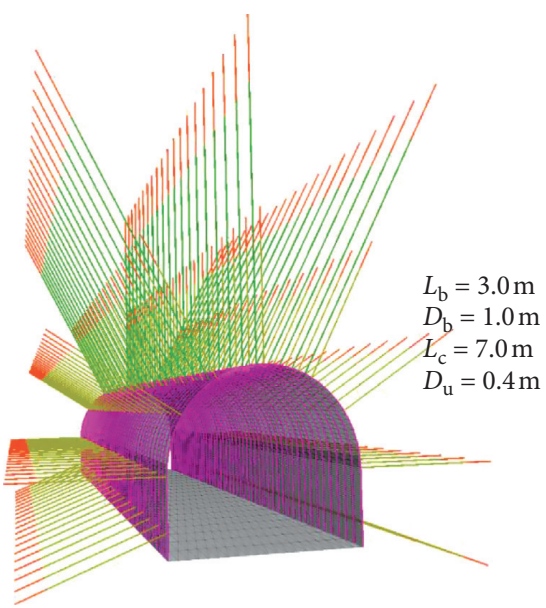

(i)

Figure 4: Numerical model of supporting structures. (a) $\mathrm{T}_{1}$. (b) $\mathrm{T}_{2}$. (c) $\mathrm{T}_{3}$. (d) $\mathrm{T}_{4} \cdot$ (e) $\mathrm{T}_{5}$. (f) $\mathrm{T}_{6}$. (g) $\mathrm{T}_{7}$. (h) $\mathrm{T}_{8}$. (i) $\mathrm{T}_{9}$.

middle of the roadway. The positive value of stress and strain indicates that the direction points to the positive direction, and the negative value indicates that the direction points to the negative direction. The numerical model is shown in Figure 5, and the mechanical parameters of the strata are shown in Table 3. 

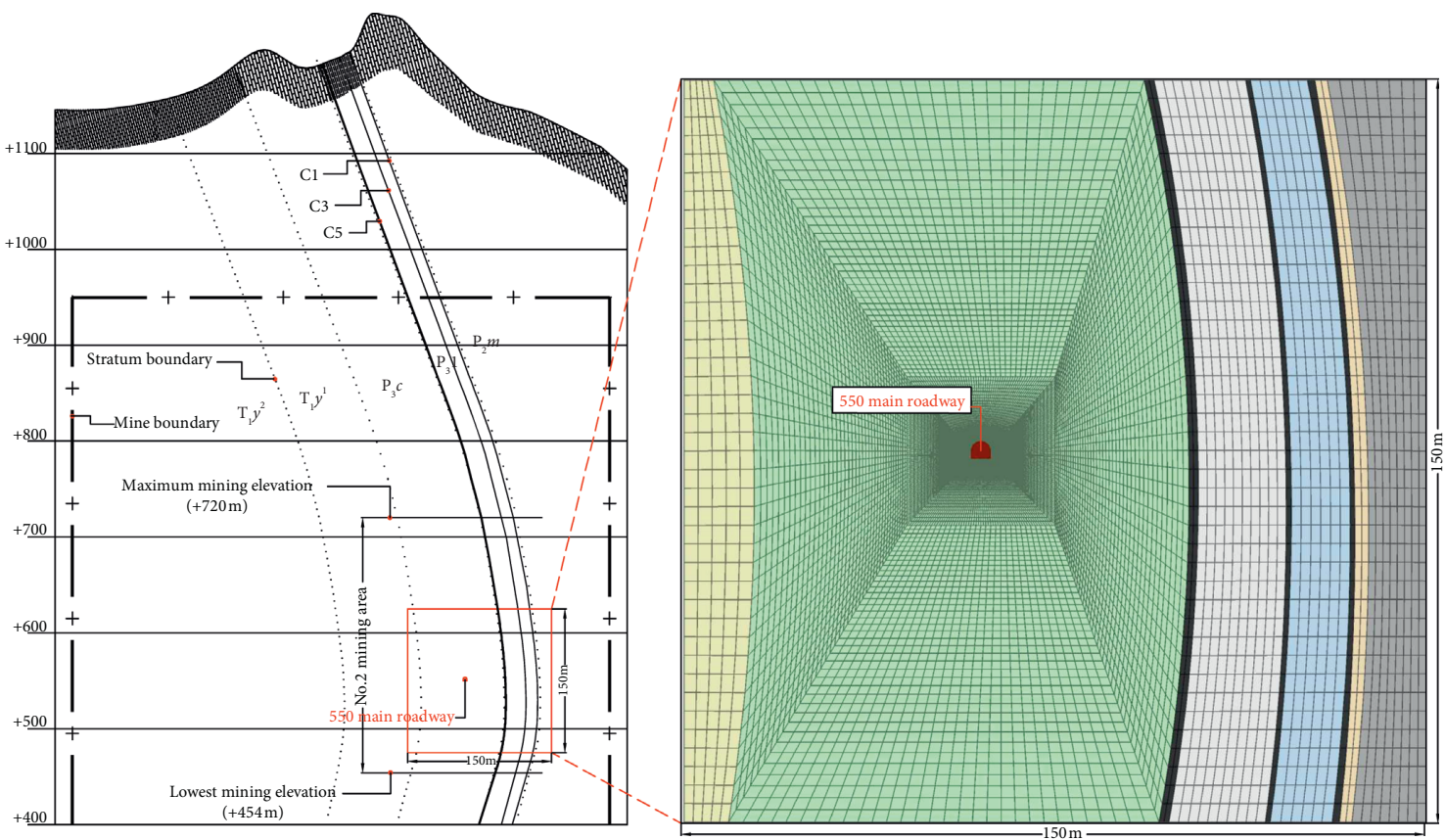

FIgURE 5: Numerical model.

TABLE 3: Rock lithology and mechanics parameters of the numerical model.

\begin{tabular}{|c|c|c|c|c|c|c|c|}
\hline \multicolumn{2}{|r|}{$\begin{array}{l}\text { Strata and main } \\
\text { lithology }\end{array}$} & \multirow{2}{*}{$\begin{array}{c}\begin{array}{c}\text { Density } \\
\left(\mathrm{kg} \cdot \mathrm{m}^{-3}\right)\end{array} \\
2720\end{array}$} & \multirow{2}{*}{$\begin{array}{c}\begin{array}{c}\text { Bulk modulus } \\
(\mathrm{GPa})\end{array} \\
2.6 \\
\end{array}$} & \multirow{2}{*}{$\begin{array}{c}\begin{array}{c}\text { Shear modulus } \\
(\mathrm{GPa})\end{array} \\
2.1 \\
\end{array}$} & \multirow{2}{*}{$\begin{array}{c}\begin{array}{c}\text { Internal friction } \\
\text { angle }\left(^{\circ}\right)\end{array} \\
31\end{array}$} & \multirow{2}{*}{$\begin{array}{c}\begin{array}{c}\text { Cohesion } \\
\text { (MPa) }\end{array} \\
2.5\end{array}$} & \multirow{2}{*}{$\begin{array}{c}\begin{array}{c}\text { Tensile strength } \\
(\mathrm{MPa})\end{array} \\
2.9 \\
\end{array}$} \\
\hline$T_{1} y^{1}$ & $\begin{array}{l}\text { Mudstone/ } \\
\text { sandstone }\end{array}$ & & & & & & \\
\hline $\mathrm{P}_{3} c$ & Bedded limestone & 2700 & 2.8 & 1.5 & 29 & 1.8 & 1.5 \\
\hline \multirow{6}{*}{$\mathrm{P}_{3} l$} & C5 coal & 1480 & 1.0 & 0.5 & 25 & 0.8 & 1.2 \\
\hline & C5 coal floor & 2720 & 2.4 & 1.5 & 29 & 2.1 & 1.2 \\
\hline & C3 coal & 1510 & 0.7 & 0.4 & 24 & 1.2 & 1.0 \\
\hline & $\mathrm{C} 1$ coal roof & 2600 & 1.7 & 1.4 & 31 & 1.5 & 1.9 \\
\hline & C1 coal & 1540 & 0.6 & 0.4 & 25 & 0.9 & 1.0 \\
\hline & C1 coal floor & 2620 & 2.1 & 1.2 & 23 & 1.2 & 1.3 \\
\hline $\mathrm{P}_{2} m$ & $\begin{array}{l}\text { Layered } \\
\text { limestone }\end{array}$ & 2710 & 3.8 & 2.5 & 30 & 2.8 & 2.8 \\
\hline
\end{tabular}

TABLE 4: Numerical calculation parameters of liner.

\begin{tabular}{lcccccc}
\hline $\begin{array}{l}\text { Young's modulus } \\
(\mathrm{GPa})\end{array}$ & $\begin{array}{c}\text { Poisson's } \\
\text { ratio }\end{array}$ & $\begin{array}{c}\text { Cohesion } \\
(\mathrm{MPa})\end{array}$ & $\begin{array}{c}\text { Friction angle } \\
\left({ }^{\circ}\right)\end{array}$ & $\begin{array}{c}\text { Thickness } \\
(\mathrm{m})\end{array}$ & $\begin{array}{c}\text { Normal stiffness }\left(10^{8}\right. \\
\left.\mathrm{N} \cdot \mathrm{m}^{-3}\right)\end{array}$ & $\begin{array}{c}\text { Shear stiffness }\left(10^{8}\right. \\
\left.\mathrm{N} \cdot \mathrm{m}^{-3}\right)\end{array}$ \\
\hline 25 & 0.2 & 3 & 50 & 0.12 & 8 & 8 \\
\hline
\end{tabular}

TABLE 5: Numerical calculation parameters of the bolt/cable.

\begin{tabular}{lcccccc}
\hline Element & $\begin{array}{c}\text { Young's modulus } \\
(\mathrm{GPa})\end{array}$ & $\begin{array}{c}\text { Cross-sectional area } \\
\left(10^{-4} \mathrm{~m}^{2}\right)\end{array}$ & $\begin{array}{c}\text { Perimeter }\left(10^{-2}\right. \\
\mathrm{m})\end{array}$ & $\begin{array}{c}\text { Cohesive strength }\left(10^{5}\right. \\
\left.\mathrm{N} \cdot \mathrm{m}^{-1}\right)\end{array}$ & $\begin{array}{c}\text { Stiffness }\left(10^{7}\right. \\
\left.\mathrm{N} \cdot \mathrm{m}^{-2}\right)\end{array}$ & $\begin{array}{c}\text { Tensile yield } \\
\text { strength }(\mathrm{kN})\end{array}$ \\
\hline Bolt & 200 & 3.8 & 9.42 & 4.3 & 2.40 & 228 \\
Cable & 195 & 3.8 & 9.42 & 1.7 & 1.12 & 607 \\
\hline
\end{tabular}


TABLE 6: Numerical calculation parameters of U-section steel.

\begin{tabular}{lcccc}
\hline $\begin{array}{l}\text { Young's modulus } \\
(\mathrm{GPa})\end{array}$ & $\begin{array}{c}\text { Poisson's } \\
\text { ratio }\end{array}$ & $\begin{array}{c}\text { Cross-sectional area }\left(10^{-4}\right. \\
\left.\mathrm{m}^{2}\right)\end{array}$ & $\begin{array}{c}\text { Second moment of the } y \text {-axis }\left(10^{-8}\right. \\
\left.\mathrm{m}^{4}\right)\end{array}$ & $\begin{array}{c}\text { Second moment of the } z \text {-axis }\left(10^{-8}\right. \\
\left.\mathrm{m}^{4}\right)\end{array}$ \\
\hline 200 & 0.3 & 45.69 & 1245 & 929 \\
\hline
\end{tabular}

5.2. Selection of Supporting Structure Parameters. Structural element liner in FLAC ${ }^{3 \mathrm{D}}$ is used to simulate reinforced wire mesh and shotcrete, and the calculation parameters are shown in Table 4 [22]. The bolts and cables are simulated by structural element cable, and the calculation parameters are shown in Table 5 [22-24]. Structural element beam is used to simulate U29 U-shaped steel, and the calculation parameters are shown in Table $6[21,22]$. The bolts' and cables' outer end is connected with the reinforced wire mesh in a node-node way to ensure its coordinated deformation. Their internal end is connected with the zone body in a node-zone way.

5.3. Numerical Simulation Calculation Results. FLAC ${ }^{3 \mathrm{D}}$ was used to calculate the above nine examination schemes. During the calculation, the deformation of the roadway was monitored. The monitoring points are arranged at $5 \mathrm{~m}, 10 \mathrm{~m}$, and $15 \mathrm{~m}$ in the model's $y$-direction. Each monitoring point monitors the roof, floor, and sidewalls of the roadway. After taking the average of the four deformations of the two gangs, the data in Table 7 are obtained. The deformations in the roadway's four directions are added to obtain the roadway's total deformation, which serves as the orthogonal test analysis index.

\section{Analysis of Orthogonal Test Results}

For the results of orthogonal experiments, there are two methods: range analysis and variance analysis. The range analysis method is simple and straightforward, and the calculation workload is small. The variance analysis can estimate the test error's size and judge whether the investigated factors' influence on the test results is significant. The purpose of this article is to propose a support structure that is prioritized to be adjusted or optimized when controlling roadway deformation. The test indicators to be investigated include roof deformation, floor deformation, two-side deformation, and total deformation. The range analysis method is used to compare the test data. Take the analysis of total deformation as an example, and the processing results are shown in Table 8 .

In Table $8, K_{i}$ is the sum of the deformation of the same level of the main control factors, $K_{i}=\sum_{i=1}^{3} y_{i}, y_{i}$ are the test results of the same level, $k=1,2,3 ; k_{i}$ is the arithmetic mean of the test results obtained when the factor in any column is set to level $i, k_{i}=K_{i} / s$, where $s$ is the number of occurrences of each level in any column; $R_{m}$ is the range of the $m$-th factor, $m=1,2,3,4$.

Table 8 is a range analysis of the influence of various factors on the roadway's total deformation. From the calculation results, it can be known that the degree of influence of the four supporting structure parameters on the deformation is $D_{\mathrm{u}}>L_{\mathrm{b}}>L_{\mathrm{c}}>D_{\mathrm{b}}$. Using the same calculation and analysis method, the above four influencing factors are used to make a range analysis of the roadway roof deformation, floor deformation, and deformation of the two sides. The results are shown in Table 9.

From the calculation results in Table 9, it can be seen that the control factors' order of the influence on the total deformation of the roadway is as follows: row spacing between U-shaped steel $>$ bolt length $>$ cable length $>$ row spacing between bolts; the order of influence on the roadway floor's deformation is as follows: row spacing between U-shaped steel $>$ row spacing between bolts $>$ bolt length $>$ cable length, same as the left sidewall and right sidewall; and the order of influence on roadway roof deformation is as follows: row spacing between $U$-shaped steel $>$ bolt length $=$ cable length $>$ row spacing between bolts.

\section{Discussions}

(1) The stability control of deep-buried underground engineering structure is a hot topic in current academic research, and it is also a problematic issue. As it has many influencing factors, some of which are related to the geological environment, some are related to the geological structure, which humans cannot control. There are also some influencing factors, such as selecting supporting materials and selecting supporting structure parameters. In particular, the series of conclusions drawn in this article is based on the site geological conditions of the Wanshun coal mine. These structures are not necessarily applicable to all deep-buried mines. The purpose of this article is to propose a research method, especially for deep mine undergrounds. When the deformation of the roadway's surrounding rock creates an acceptable range, it needs to be adjusted. When adjusting, it is necessary to distinguish the primary and secondary relationship of the factors affecting the roadway's deformation, analyze the influence degree of different support structure parameters, and maximize control of the roadway's surrounding rock's deformation.

(2) The conclusions are subject to specific conditions. Only under the conditions described in this paper or similar conditions will the conclusions be applicable. If the conditions change, the conclusions will be different. This paper provides a solution when the deformation of roadway at the coal mine site cannot be controlled, and the support parameters need to be adjusted. That is, the orthogonal test method is used to rank the influence degree of the adjustable parameters 
TABLE 7: Monitoring values of roadway deformation.

\begin{tabular}{|c|c|c|c|c|c|}
\hline Test number & Roof (mm) & Floor $(\mathrm{mm})$ & Left sidewall $(\mathrm{mm})$ & Right sidewall (mm) & Total deformation $(\mathrm{mm})$ \\
\hline $\mathrm{T}_{1}$ & 30 & 91 & 51 & 49 & 221 \\
\hline $\mathrm{T}_{2}$ & 43 & 90 & 55 & 52 & 240 \\
\hline $\mathrm{T}_{3}$ & 75 & 93 & 62 & 57 & 287 \\
\hline $\mathrm{T}_{4}$ & 55 & 93 & 57 & 54 & 259 \\
\hline $\mathrm{T}_{5}$ & 30 & 89 & 51 & 49 & 219 \\
\hline $\mathrm{T}_{6}$ & 35 & 89 & 55 & 52 & 231 \\
\hline $\mathrm{T}_{7}$ & 44 & 91 & 53 & 49 & 237 \\
\hline $\mathrm{T}_{8}$ & 56 & 92 & 57 & 54 & 259 \\
\hline $\mathrm{T}_{9}$ & 31 & 89 & 52 & 50 & 222 \\
\hline
\end{tabular}

TABLE 8: Range analysis of the main control factors.

\begin{tabular}{|c|c|c|c|c|c|}
\hline \multirow{2}{*}{ No. } & \multicolumn{4}{|c|}{ Control factor } & \multirow{2}{*}{ Total deformation (mm) } \\
\hline & Bolt length & Row spacing between bolts & Cable length & Row spacing in U-shaped steel & \\
\hline $\mathrm{T}_{1}$ & $1(2.0)$ & $1(0.6 \times 0.6)$ & $1(5.0)$ & $1(0.4)$ & 221 \\
\hline $\mathrm{T}_{2}$ & 1 & $2(0.8 \times 0.8)$ & $2(7.0)$ & $2(0.7)$ & 240 \\
\hline $\mathrm{T}_{3}$ & 1 & $3(1.0 \times 1.0)$ & $3(9.0)$ & $3(1.0)$ & 287 \\
\hline $\mathrm{T}_{4}$ & $2(2.5)$ & 1 & 2 & 3 & 259 \\
\hline $\mathrm{T}_{5}$ & 2 & 2 & 3 & 1 & 219 \\
\hline $\mathrm{T}_{6}$ & 2 & 3 & 1 & 2 & 231 \\
\hline $\mathrm{T}_{7}$ & $3(3.0)$ & 1 & 3 & 2 & 237 \\
\hline $\mathrm{T}_{8}$ & 3 & 2 & 1 & 3 & 259 \\
\hline $\mathrm{T}_{9}$ & 3 & 3 & 2 & 1 & 222 \\
\hline$K_{1}$ & 748 & 717 & 711 & 662 & \\
\hline$K_{2}$ & 709 & 718 & 721 & 708 & \\
\hline$K_{3}$ & 718 & 740 & 743 & 805 & \\
\hline$k_{1}$ & 249.3 & 239.0 & 237.0 & 220.7 & \\
\hline$k_{2}$ & 236.3 & 239.3 & 240.3 & 236.0 & \\
\hline$k_{3}$ & 239.3 & 246.7 & 247.7 & 268.3 & \\
\hline$R_{m}$ & 13.0 & 7.7 & 10.7 & 47.7 & \\
\hline
\end{tabular}

TABLe 9: The range of calculation results for each factor.

\begin{tabular}{|c|c|c|c|c|c|}
\hline \multirow{2}{*}{ Item } & \multicolumn{4}{|c|}{ Control factor } & \multirow{2}{*}{ The order of control factors } \\
\hline & Bolt length & Row spacing between bolts & Cable length & Row spacing in U-shaped steel & \\
\hline Roof, $R$ & 9.3 & 4.0 & 9.3 & 31.7 & $D_{\mathrm{u}}>L_{\mathrm{b}}=L_{\mathrm{c}}>D_{\mathrm{b}}$ \\
\hline Floor, $R$ & 1.0 & 1.3 & 0.3 & 3.0 & $D_{\mathrm{u}}>D_{\mathrm{b}}>L_{\mathrm{b}}>L_{\mathrm{c}}$ \\
\hline Left sidewall, $R$ & 2.0 & 2.7 & 1.0 & 7.3 & $D_{\mathrm{u}}>D_{\mathrm{b}}>L_{\mathrm{b}}>L_{\mathrm{c}}$ \\
\hline Right sidewall, $R$ & 1.7 & 2.3 & 0.3 & 5.7 & $D_{\mathrm{u}}>D_{\mathrm{b}}>L_{\mathrm{b}}>L_{\mathrm{c}}$ \\
\hline Total deformation, $R$ & 13.0 & 7.7 & 10.7 & 47.7 & $D_{\mathrm{u}}>L_{\mathrm{b}}>L_{\mathrm{c}}>D_{\mathrm{b}}$ \\
\hline
\end{tabular}

for comparison. Under the minimum adjustment work, the best support effect can be obtained.

(3) The orthogonal test with four factors and three levels was chosen in the paper, and no empty column was set. In this case, the variance analysis cannot be performed. To reduce the calculation amount in numerical simulation, this paper considers four control factors, and each control factor sets three levels. However, there are still many factors that can be considered, such as different buried depths, different anchor cable layout schemes, the layout of the roadway floor bolts, and whether to use grouting reinforcement. More research on these needs to be done later.

\section{Conclusions}

(1) The deformation of the surrounding rock mass roadway with deep-buried fissures was investigated on site, and it was found that the support of this type of roadway is complex, the failure of the support structure often occurs, and some require multiple repairs. Peeping through drilling holes in the surrounding rock of the roadway, it is found that, due to the excavation of the roadway, the stress of the surrounding rock mass is relieved, resulting in cavities and separation, and the development of the cracks in the two sidewalls and the roof is mainly tangential. 
(2) The multi-index orthogonal design was adopted to carry out various combinations of supporting structure parameters to determine the degree of influence of the supporting structure parameters on the supporting effect. The bolt length, row spacing between bolts, cable length, and row spacing between U-shaped steel are selected as the main control factors, and the total deformation of the roadway roof, floor, two sidewalls, and the roadway is used as the examination index. Nine numerical simulation schemes were designed based on orthogonal experiments, and a numerical model consistent with the geological conditions of the coal mine site was established using FLAC ${ }^{3 \mathrm{D}}$. Numerical calculations were carried out to simulate the ground pressure conditions under the condition of deep burial at the site.

(3) The test results were analyzed by range analysis. It was found that the control factors' influence order on the total deformation of the roadway is as follows: row spacing between U-shaped steel > bolt length$>$ cable length > row spacing between bolts; the influence order on the deformation of the roadway floor is as follows: row spacing between U-shaped steel $>$ row spacing between bolts $>$ bolt length$>$ cable length, same as the left sidewall and right sidewall; and the influence order on the roadway roof s deformation is as follows: row spacing between U-shaped steel $>$ bolt length $=$ cable length $>$ row spacing between bolts.

\section{Data Availability}

The data used to support the findings of this study are included within the article.

\section{Conflicts of Interest}

All the authors declare that they have no conflicts of interest.

\section{Acknowledgments}

This research was supported by the National Natural Science Foundation of China (nos. 51974117, 51764010, and 51874109), Science and Technology Project for Outing and Young Talents of Guizhou (Talents of Science Platform in Guizhou; no. [2019] 5674), New Talent Training Project of Guizhou Institute of Technology (no. GZLGXM-02), Hunan Provincial Natural Science Foundation of China (no. 2020JJ4027), Guizhou Provincial Science and Technology Support Program (no. QKHZC[2021]General 347), and Scientific Research Foundation for High-Level Talents in Guizhou Institute of Technology (no. XJGC20190633). Professor Xueling Du from Guizhou Institute of Technology had provided a lot of valuable opinions on this article. The authors would like to express their sincere thanks to Professor Du.

\section{References}

[1] H. Kang, "Support technologies for deep and complex roadways in underground coal mines: a review," International Journal of Coal Science \& Technology, vol. 1, no. 3, pp. 261-277, 2014.

[2] Z. Zhang, J. Bai, Y. Chen, and S. Yan, "An innovative approach for gob-side entry retaining in highly gassy fullymechanized longwall top-coal caving," International Journal of Rock Mechanics and Mining Sciences, vol. 80, pp. 1-11, 2015.

[3] M. Kanji, M. C. He, and L. R. Sousa, Soft Rock Mechanics and Engineering, Springer, Berlin, Germany, 2020.

[4] A. Batugin, Z. Q. Wang, Z. H. Su, and S. S. Sidikovna, "Combined support mechanism of rock bolts and anchor cables for adjacent roadways in the external staggered splitlevel panel layout," International Journal of Coal Science \& Technology, pp. 1-15, 2021.

[5] W. Yu, G. Wu, B. Pan, Q. Wu, and Z. Liao, "Experimental investigation of the mechanical properties of sandstone-coalbolt specimens with different angles under conventional triaxial compression," International Journal of Geomechanics, vol. 21, no. 6, Article ID 04021067, 2021.

[6] G. Wu, W. Yu, J. Zuo, and S. Du, "Experimental and theoretical investigation on mechanisms performance of the rockcoal-bolt (RCB) composite system," International Journal of Mining Science and Technology, vol. 30, no. 6, pp. 759-768, 2020.

[7] F. Gong, W. Wu, T. Li, and X. Si, "Experimental simulation and investigation of spalling failure of rectangular tunnel under different three-dimensional stress states," International Journal of Rock Mechanics and Mining Sciences, vol. 122, Article ID 104081, 2019.

[8] S.-c. Li, H.-t. Wang, Q. Wang et al., "Failure mechanism of bolting support and high-strength bolt-grouting technology for deep and soft surrounding rock with high stress," Journal of Central South University, vol. 23, no. 2, pp. 440-448, 2016.

[9] Z. Zhang, M. Deng, J. Bai, X. Yu, Q. Wu, and L. Jiang, "Strain energy evolution and conversion under triaxial unloading confining pressure tests due to gob-side entry retained," International Journal of Rock Mechanics and Mining Sciences, vol. 126, Article ID 104184, 2020.

[10] J. P. Zuo and J. Y. Shen, The Hoek-Brown Failure Criterionfrom Theory to Application, Springer, Singapore, 2020.

[11] J. Li, N. J. Ma, and Z. W. Ding, "Heterogeneous large deformation mechanism based on change of principal stress direction in deep gob side entry and control," Journal of Mining and Safety Engineering, vol. 35, no. 4, pp. 670-676, 2018.

[12] H. Zhang, J. Cao, and M. Tu, "Floor stress evolution laws and its effect on stability of floor roadway," International Journal of Mining Science and Technology, vol. 23, no. 5, pp. 631-636, 2013.

[13] W. P. Li, M. Y. Wang, P. X. Fan, and H. J. Deng, "Study of deformation and failure model for deep rock mass and its numerical method," Chinese Journal of Rock Mechanics and Engineering, vol. 30, no. 6, pp. 1250-1257, 2011.

[14] B. X. Huang, N. Zhang, H. W. Jing et al., "Large deformation theory of rheology and structural instability of the surrounding rock in deep mining roadway," Journal of China Coal Society, vol. 45, no. 3, pp. 911-926, 2020.

[15] S. Yan, Y. Song, J. Bai, and D. Elmo, "A study on the failure of resin end-anchored rockbolts subjected to tensile load," ROck Mechanics and Rock Engineering, vol. 52, no. 6, pp. 1917-1930, 2019. 
[16] D. Zhu, Y. Wu, Z. Liu, X. Dong, and J. Yu, "Failure mechanism and safety control strategy for laminated roof of widespan roadway," Engineering Failure Analysis, vol. 111, Article ID 104489, 2020.

[17] H. Yu, Z. Niu, L. Kong, C. Hao, and P. Cao, "Mechanism and technology study of collaborative support with long and short bolts in large-deformation roadways," International Journal of Mining Science and Technology, vol. 25, no. 4, pp. 587-593, 2015.

[18] P. Nikolenko, S. Epshtein, V. Shkuratnik, and P. Anufrenkova, "Experimental study of coal fracture dynamics under the influence of cyclic freezing-thawing using shear elastic waves," International Journal of Coal Science \& Technology, 2020.

[19] R. Wang, J.-b. Bai, S. Yan, Y.-b. Song, and G.-d. Wang, “An improved numerical simulation approach for the failure of rock bolts subjected to tensile load in deep roadway," Geofluids, vol. 2020, Article ID 8888390, 21 pages, 2020.

[20] J. Sun, L. G. Wang, F. R. Tang, and Y. F. Shen, "Microseismic monitoring failure characteristics of inclined coal seam floor," Rock and Soil Mechanics, vol. 32, no. 5, pp. 1589-1595, 2011.

[21] X. T. Feng, Rock Mechanics and Engineering Volume 4, Excavation, Support and Monitoring, CRC Press, Boca Raton, FL, USA, 2016.

[22] ITASCA Consulting Group Inc., Help and Documentation, ITASCA Consulting Group Inc., Minneapolis, MIN, USA, 2019.

[23] W. J. Yu, K. Li, Q. H. Lu, H. X. Guo, and S. H. Du, "Engineering characteristics and deformation control of roadways in fractured rock mass," Journal of China Coal Society, pp. 1-12, 2021.

[24] F. Q. Gao, Simulation of Failure Mechanisms Around Underground Coal Mine Openings Using Discrete Element Modelling, Simon Fraser University, Burnaby, Canada, 2013. 